Research Article

\title{
Characterizing the Digital Culture of Prospective Primary School Teachers
}

\author{
Youssef Ou-sekou $\mathbb{D},{ }^{1}$ Fatiha kaddari $\mathbb{D},{ }^{1}$ and Abdelkarim Zaid $\mathbb{D}^{2}$ \\ ${ }^{1}$ Sidi Mohamed BenAbdellah University Morocco, Laboratory LISAC FSDM, Fez, Morocco \\ ${ }^{2}$ University of Lille Nord de France, 2ESPE LNF-Graduate School of Teaching and Education, Lille, France \\ Correspondence should be addressed to Youssef Ou-sekou; youssef.ousekou@usmba.ac.ma
}

Received 4 April 2021; Accepted 19 June 2021; Published 1 July 2021

Academic Editor: Ehsan Namaziandost

Copyright (c) 2021 Youssef Ou-sekou et al. This is an open access article distributed under the Creative Commons Attribution License, which permits unrestricted use, distribution, and reproduction in any medium, provided the original work is properly cited.

\begin{abstract}
This article aims at characterizing the digital culture of prospective Moroccan primary school teachers during their training. The study was conducted as a survey on a sample of prospective primary school teachers from Morocco. A descriptive frequency analysis was performed using SPSS. The results show that this digital culture is rooted more considerably in their personal use of different technological tools or resources. The article analyzes the resources of digital culture through the objectives of digital practices of prospective teachers and the motivations underlying their choice of a specific digital tool and practice. The digital practices of prospective teachers are marked by frequent use of social networks and a low tendency to make use of institutional platforms and their trainers' blogs. The analysis highlights the nature of the environments, services, and digital resources manipulated by prospective teachers during their training. It also sheds light on the role of this digital culture in the content preparation activities of these potential teachers, as well as the resources produced by them and by their trainers. The preparation of pedagogical content often makes use of social network tools, while educational tools are in average use. Finally, the results show that these exchanges are dominated by WhatsApp, Google Drive, and e-mail; however, the use of the WhatsApp application is more prevalent when interacting with trainers.
\end{abstract}

\section{Introduction}

Digital technologies have radically changed society and the economy. Society has become more modern and the economy is moving toward complete digitalization. All these factors have led education specialists and researchers to conduct research on the need to modernize education to cope with changes in society and the economy. According to Prensky [1], modern society is characterized by two generations: the "digital natives" and "digital immigrants". For Prensky [1], the natives are a generation born in the digital age, who do not lack the knowledge and technical skills to manipulate all kinds of tools in different contexts, while the immigrants are those who were not born in the digital age, but they are fascinated by technologies; they strive to take advantage of this digital world. For Prensky, teachers/ trainers (digital immigrants) have difficulty teaching/ training young people (digital natives) who speak an entirely digital language.

A gap has, therefore, been noticed between the digital practices of young people and those offered to them at school. Indeed, the digital uses and practices of young people alternate between their personal spheres and school forms according to their needs [2]. Other research [3] affirms that if young people show frequent use of digital tools in personal contexts, this does not necessarily imply that they master them in professional or academic contexts. Young people often use these digital tools for leisure and social digital practices [4, 5]. Poyet [6], Benett and Maton [7], and Barron et al. [8] invite us to approach this divide not from a generational point of view (i.e., between "immigrants" which could include teachers and trainers) and "natives" (students, young teachers) but rather from the point of view of the tension generated between the two spheres: the personal 
digital sphere and the school sphere. Other research [9] emphasizes various possible developments focusing on teachers' and young people's practices, taking into consideration the differences between "ideal" or expected school practices and actual personal practices and also the differences between the objectives of each act of learning and the learner's satisfaction.

In Morocco, the initial training of teachers is a major challenge and constitutes an essential lever for the modernization of the education system [10] (the Strategic Vision of the 2015-2030 reform in Morocco1). The integration and use of educational technologies in teacher training centers are, thus, a major concern for educational managers. This is evidenced by the insistence of official texts, particularly those defining the Strategic Vision of the 2015-2030 reform in Morocco, on "the shift from the logic of linear transmission of knowledge and memorization to a logic of learning, developing a sense of criticism, constructing a personal project, acquiring languages, knowledge, skills, values, digital technologies" and, more specifically, on the implementation of "Educational technologies by developing a national strategy which will put them at the educational service quality at the level of curricula, programs, and training from the first school years throughout the various digital media, interactive programs, and networks."

The initial question that prompted this study is rooted in a Moroccan context that is marked by a gap between the expectations of official instructions regarding the use of technologies by prospective teachers during training and their actual digital practices. The research question is formulated as follows: what are the dominant uses in the digital practices of prospective teachers and why? This question will be further broken down into subquestions after the theoretical framework has been developed.

\section{Theoretical Framework}

The notion of culture is polysemous. Its definitions can generally be either materialist or "idealist" [11]. According to this author, the classical materialist interpretation of culture focuses on behavior and covers the sum of all models or observable behaviors of customs and ways of life of a particular social group, whereas the most popular idealist definition of culture is the cognitive definition which includes ideas, beliefs, and knowledge that characterize a particular group of people. Both types of definitions are useful for exploring how groups of people think and behave in their environment. The first appearance of the concept of "digital literacy" was in the 2000s at the conference (O'Reilly Emerging Technologies 2004) that was held under the theme "To shape the future, you have to be there." A first definition of the concept of digital culture was adopted during this conference; this definition includes all the tools of Web 2.0 and all the interactive technologies. The other definitions given to the concept of "digital culture" in other research are divided into two categories. The first one characterizes it as a purely technological phenomenon, while the other one considers it as a phenomenon of humanitarian dimension besides technological.
According to Bayeva [12], digital culture is considered a purely technological phenomenon, as all the components of this culture are digital tools, be it hardware or software. In this sense, the concept "digital culture" refers to the appropriation of techniques to the development of its uses and to the representations, the values, the beliefs, and the products that result from it [6]. Fluckiger [13] builds his definition on the set of values, knowledge, and practices involving the use of technologies; these generate consumption practices of media, culture, communication, and self-expression among young people. The definition given by Greenhow and Lewin [14] addresses digital literacy in its participatory dimension during activities using platforms and social networks.

The researchers Chernykh and Parshikov [15] have stated that digital culture influences the individual in a humanitarian way beyond the technological influence, and therefore, it brings about changes to the person's environment and subsequently the person themselves.

In other studies, we have found that the concept of digital culture can be used as electronic culture. In this direction, the researcher Krivosheev [16] defines the concept of "electronic culture" as follows: "An essential characteristic of modern society; it permeates all the content of social life and modifies it. Electronic culture, as an exceptionally multifaceted reality, requires not only a certain understanding or a consideration among several others, but also a thorough interdisciplinary study because it is not just a component of something more complex, but a system that itself determines all facets of the functioning of modern society".

From these different perspectives, we have identified three common features of digital culture: its references characterized by the dominant digital uses and practices among young people and in our case prospective teachers, the products that result from these practices and uses, in terms of content, resources produced, etc., and the communication or exchanges through the digital tools used [17].

Our contribution will investigate the digital culture of prospective teachers by characterizing the resources, i.e., their dominant digital practices, tools, and materials; the traces of personal culture of prospective teachers during training in terms of tools used to prepare the contents and also the productions of prospective teachers; and the tools frequently used during exchanges between prospective teachers and their trainers. Thus, the research question will be broken down into three subquestions:

(1) What resources do prospective teachers use (professional or rather personal or playful digital practices)?

(2) How do prospective teachers deploy digital tools during training activities?

(3) What tools do prospective teachers frequently use during exchanges with their trainers?

The experimental part of the study involved 56 prospective teachers from the Center of Education and Training (CRMEF), Meknes, Morocco. The questionnaire aims to 
TABLE 1: Structure of the first part of the questionnaire.

\begin{tabular}{lc}
\hline Item 1 & Digital practices covering social networks, Office, games, blogs.... \\
Item 2 & Motivations: self-expression \\
Item 3 & Nature of the applications/services used \\
Item 4 & Nature of the resources used \\
Item 5 & Nature of digital environments used: academic, personal, mixed \\
Item 6 & Objectives of digital practices: leisure, learning ... \\
Item 7 & Number of institutional web portals visited? \\
Item 8 & Number of personal blogs of prospective teachers \\
Item 9 & Number of visits to trainers' personal blogs
\end{tabular}

categorize the digital practices of the prospective teachers, as well as the content produced during training, and finally to determine the digital tools that dominate their exchanges with their trainers. All these results will allow us to characterize the digital culture of these prospective teachers.

\section{Methodology}

3.1. Design. The research was a case study that was conducted among the prospective teachers at the Regional Center for Education and Training (CRMEF), Meknes, Morocco. Approval to conduct the study was granted by the Center for Education and Training (CRMEF), Meknes. The study process was completely anonymous, and no personal identifiers were used in the study.

3.2. Participants. The participants of this work were 56 students in primary education training at the Regional Center for Education and Training (CRMEF), Meknes, Morocco. These students hold at least a Bachelor's degree from various disciplines, such as sciences (Mathematics, Physics, Chemistry, Biology, etc.), human sciences (French literature, English studies, Arabic literature, History, and civilization, etc.) in addition to economic and social sciences. The descriptive analysis of the results shows that among the 56 prospective teachers of the CRMEF MEKNES center who participated in the research, 41 were women $(73.2 \%)$ and 15 were men $(26.8 \%)$. The dominant age group is that between 26 years and 30 years old (42.9\%); the minority group is that between 31 years and 35 years old (12.5\%). Graduates dominate $(83.9 \%)$; while 8 prospective teachers have obtained their master's degrees (14.3\%), only one prospective teacher reported having a national doctorate. The science and technology specialty fields represent $41.1 \%$; the humanities, 30.4\%; and the economic and legal sciences, $28.6 \%$.

3.3. Instrument. A paper version of the questionnaire was distributed. The questionnaire was designed to document the three dimensions of the digital culture of prospective teachers: the resources (9 multiple choice questions) and the tools used during the preparation of the content and the exchanges with the trainers (8 multiple choice questions). Organized in two parts, the questionnaire also included questions investigating demographic data (sex, age, field of training, and educational level, whether or not the prospective teacher has received training in educational technology). The structure of the two parts of the questionnaire is shown in Tables 1 and 2.

3.4. Data Collection Procedure. A paper version of the questionnaire was distributed. The use of the questionnaire was face-to-face, to answer all the questions and remove any ambiguity about the items proposed. After collection of all questionnaires. The data were entered into SPSS version 23.0.

3.5. Data Analysis. The data collected was processed and analyzed by SPSS. Multiple choice questions were used in parts 1 and 2 of the questionnaire, offering a predefined list of choices, and end with the choice "other" allowing each participant to enter his or her answer. To analyze the results with SPSS for multiple choice questions, the answer to each question was coded under a single variable. Descriptive statistics were used to present the results in text, tables, and figures. Means and standard deviations were calculated for numerical data, while frequencies and percentages were calculated for categorical data.

Cronbach's alpha is less than 0.70 , and after the elimination of the item questioning the teaching experience, this coefficient is of the order of 0.736 (Table 3 ), which indicates a good internal consistency of the scales [18].

Multiple choice questions were used in parts 1 and 2 of the questionnaire, offering a predefined list of choices, and end with the choice "other" allowing each participant to enter his or her answer. To analyze the results with SPSS for multiple choice questions, the answer to each question was coded under a single variable. A descriptive frequency analysis for each variable obtained was performed using SPSS.

\section{Results}

4.1. Characterization of Digital Practices of Prospective Teachers. The descriptive analysis of the results shows that among the 56 prospective teachers of the CRMEF MEKNES center who participated in the research, 41 were women (73.2\%) and 15 were men $(26.8 \%)$. The dominant age group is that between 26 years and 30 years old (42.9\%); the minority group is that between 31 years and 35 years old $(12.5 \%)$. Graduates dominate $(83.9 \%)$; while 8 prospective teachers have obtained their master's degrees (14.3\%), only one prospective teacher reported having a national doctorate. The science and technology specialty field represent 
TABLE 2: Structure of the second part of the questionnaire.

\begin{tabular}{lc}
\hline Item 1 & $\begin{array}{c}\text { The tools used for individual preparation of teaching content: Facebook, WhatsApp ... } \\
\text { Item } 2 \\
\text { The tools used for group preparation of teaching content: Facebook, WhatsApp ... } \\
\text { Item } 3\end{array}$ Reasons for using tools for preparation: easy to use, assistance services ... \\
Item 4 & Services/resources considered essential: communication, access to courses ... \\
Item 5 & The equipment used: cell phone, tablet ... \\
Item 6 & The productions of prospective teachers: digital texts, video ... \\
Item 7 & The outputs of the trainers: digital texts, video ... \\
Item 8 & The exchanges with the trainers by means of Facebook, WhatsApp...
\end{tabular}

TABLe 3: Reliability statistics.

TABle 4: Dominant digital practices among prospective teachers.

\begin{tabular}{lcc}
\hline Dominant digital practices & Number of prospective teachers & Percentage of observations \\
\hline Social networks & 49 & 87.5 \\
Office software & 45 & 80.4 \\
Games & 19 & 33.9 \\
IT security & 1 & 1.8 \\
Personal blog & 7 & 12.5 \\
\hline
\end{tabular}

TABLE 5: The different motivations for choosing between digital tools.

\begin{tabular}{lcc}
\hline Motivations justifying the choice of digital practices & Number of prospective teachers & Percentage of observations \\
\hline Self-expression & 29 & 53.7 \\
Free & 23 & 42.6 \\
Respect for private life & 4 & 7.4 \\
Unlimited exchange & 20 & 37.0 \\
Environment adapted to your personal needs & 40 & 74.1 \\
Easy to use & 35 & 64.8 \\
\hline
\end{tabular}

41.1\%; the humanities, $30.4 \%$; and the economic and legal sciences, $28.6 \%$.

The multiple choice responses to the question concerning personal digital practices were coded as a single variable. Table 4 summarizes the results.

The results show that $87.5 \%$ of the respondents often use social networks; the use of office tools is considerably important as $80.4 \%$ of these prospective teachers reported using these tools. The minority practices are those concerning digital games (33.9\%), personal blogs (12.5\%), and finally computer security $(1.8 \%)$.

\subsection{What Motivates Prospective Teachers to Choose a Digital} Practice? In order to choose between these digital practices revealed in the first question, the motivations prompting the choices of prospective teachers during the first question were investigated. Indeed, this motivation among prospective teachers is of paramount value as a factor that influences academic success [19-21]; other researchers consider it to be a key factor for a successful achievement of learning outcomes [20].

The results show that digital environments that meet the personal needs of prospective teachers are dominant $(74.1 \%)$ while $(64.8 \%)$ prefer easy-to-use digital tools. More than half of these prospective teachers $(53.7 \%)$ are motivated by the freedom of self-expression via the digital tool manipulated, while $42.6 \%$ are motivated by the fact that they are free of charge, others (37\%) are motivated by "unlimited" communication, and finally, only $7.4 \%$ are motivated by "respect for private life" which ranks last among all the motivations. Table 5 illustrates the results obtained.

4.3. What Are the Objectives for the Digital Practices of Prospective Teachers? In order to characterize the objectives of the digital practices of prospective teachers during training, each prospective teacher must choose between several types of practice: leisure (entertainment, games, etc.), learning, and interaction with peers or with trainers.

Multiple choice responses to the question regarding the purpose of digital practices were coded as a single variable. The digital practices whose goal is learning are the most dominant: $92.7 \%$ asserted that the goal of their digital practices is learning, followed by communication practices with peers (76.4\%). Leisure occupies an important part of the practices of prospective teachers (63.6\%). More than half (56.4\%) of prospective teachers stated that they aim for interactions with their trainers during their digital practices (Table 6). 
TABLE 6: The objectives of the digital practices of prospective teachers.

\begin{tabular}{lcc}
\hline The objectives of digital practices & Number of prospective teachers & Percentage of observations \\
\hline Leisure & 35 & 63.6 \\
Learning & 51 & 92.7 \\
Interaction with peers & 42 & 76.4 \\
Interaction with trainers & 31 & 56.4 \\
Other goals for personal digital practices & 1 & 1.8 \\
\hline
\end{tabular}

TABLE 7: The nature of digital environments handled by prospective teachers.

\begin{tabular}{lcc}
\hline The nature of the environment & $\begin{array}{c}\text { Number of } \\
\text { prospective teachers }\end{array}$ & Percentage of observations \\
\hline Academic environment (institutional portal, official website) & 16 & 29.1 \\
Personal environment (personal blog, personal page on one of the social networks) & 17 & 30.9 \\
Mixed environment & 38 & 69.1 \\
\hline
\end{tabular}

TABLE 8: The nature of the services that dominate the digital practices of prospective teachers.

\begin{tabular}{lcc}
\hline The nature of the services and applications & Number of prospective teachers & Percentage of observations \\
\hline Free service & 41 & 74.5 \\
Paid service & 12 & 21.8 \\
Trial version service & 14 & 25.5 \\
Hacked service & 41 & 74.5 \\
Other services & 2 & 3.6 \\
\hline
\end{tabular}

The digital tools that prospective teachers choose offer environments that differ from one tool to another. An investigation of the types of environment that these digital tools offer was carried out. The environments are classified into three categories: academic environments (for example, an institutional web portal, an official website), personal environments (for example, a personal blog of an experienced teacher or trainer, a personal page on one of the social networks), and mixed environments, offering both academic and personal aspects in their environment.

4.4. The Nature of the Environments Offered by the Digital Tools Used. A significant trend among prospective teachers is the use of mixed environments. $69.1 \%$ of prospective teachers reported working in mixed environments, followed by $30.9 \%$ in personal environments and finally $29.1 \%$ in academic environments. Each digital environment provides a range of different services and resources during manipulation. These services and resources are either completely free of charge (may contain disruptive ads) or paid ones. Table 7 summarizes these results.

4.5. The Nature of the Resources Handled. Multiple choice responses to the question regarding the nature of services and resources used were coded as a single variable: one for services and another for resources. The results affirm that the majority of prospective teachers tend to use either free or pirated services and apps (74.5\%), while $25.5 \%$ use trial versions and $21.8 \%$ claim to have used paid digital services and applications (Table 8).
As for the resources, it is obvious that free resources are the most dominant ( $83.9 \%$ reported using free resources). Half of the participants claim that they use pirated resources, while a minority $(8.9 \%)$ pay fees to have access to resources through the tools they use (Table 9).

4.6. Preparation of Content and Nature of Productions. After the description of the dominant digital practices among prospective teachers, the digital environments used, the nature of the services and resources manipulated, and the objectives of these digital practices, we attempt in this section to analyze how these prospective teachers deploy their digital culture to prepare content during training. We will discuss their individual and group preparations as well.

The choice of digital tools when preparing pedagogical content involves the use of specific hardware. The results show that the majority of prospective teachers use their mobile phones when preparing content (98.2\% said they use smartphones). $76.8 \%$ use laptops, while just a minority use tablets $(7.1 \%)$ and desktop computers $(8.9 \%)$ as material resources.

4.6.1. Individual Preparation of Content. Among the social media tools, there are two preeminent social media platforms that dominate the individual preparation of the content of prospective teachers, YouTube (82\%) and WhatsApp $(78 \%)$, while $38 \%$ of prospective teachers said they use Facebook during their individual preparations. Instagram ranks last, as only 3 prospective teachers reported using it in their preparations. Among the cloud-based tools, Google Drive dominates the individual preparations 
TABLE 9: The nature of the resource that dominates the digital practices of prospective teachers.

\begin{tabular}{lcc}
\hline The nature of resources & Number of prospective teachers & Percentage of observations \\
\hline Free resources & 47 & 83.9 \\
Paid resources & 5 & 8.9 \\
Hacked resources & 28 & 50.0 \\
\hline
\end{tabular}

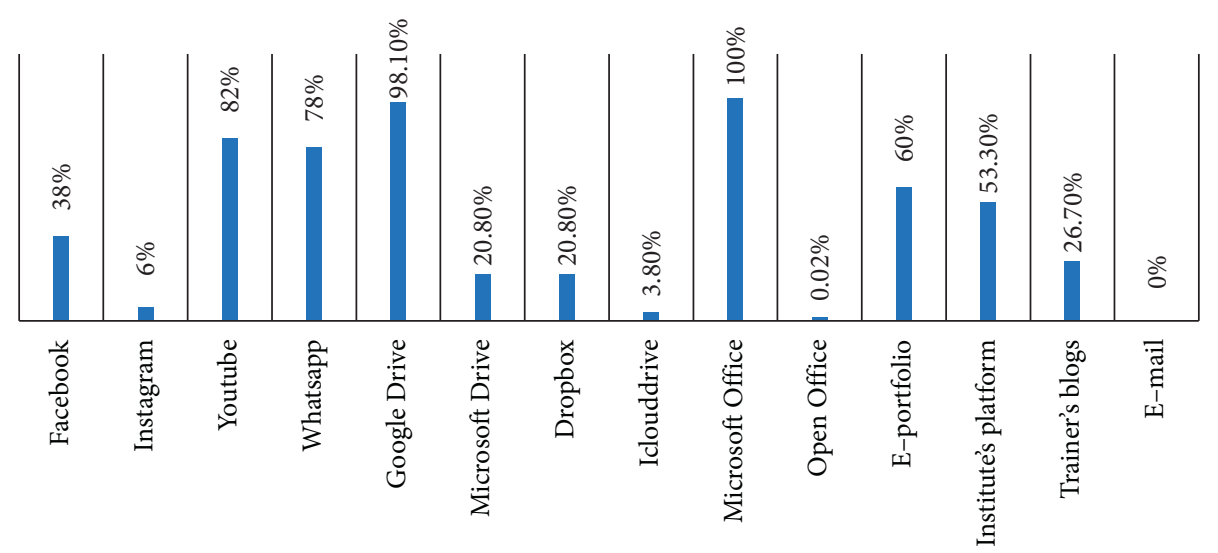

FIgURE 1: The different digital tools used during the individual preparation of content.

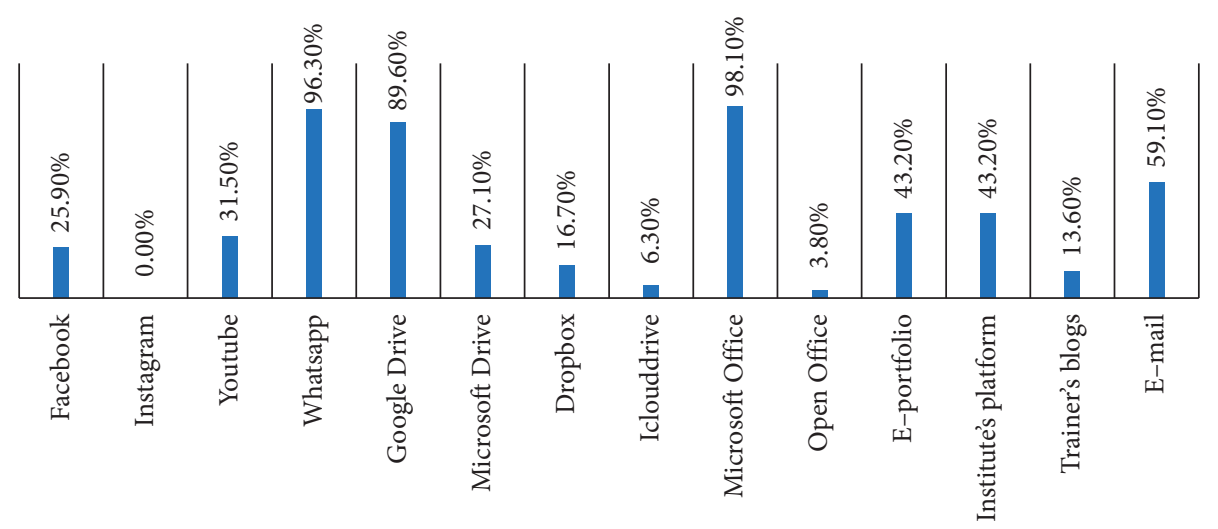

FIGURE 2: The various digital tools used during group preparation of content.

(98.1\%), with 11 prospective teachers reporting equal use of the two tools from Microsoft OneDrive (20.8\%) and Dropbox (20.8\%). Microsoft's office tools dominate the individual preparations of prospective teachers. $100 \%$ of prospective teachers reported using these tools in their individual preparations while only one prospective teacher indicated that he uses Open Office. Concerning the tools classified as pedagogical devices, the e-portfolios dominate the tools prospective teachers use during their individual preparation $(60 \%)$, followed by the training center platform (53.3\%). As for personal blogs, 12 prospective teachers (26.7\%) stated that they use them during their individual preparations (Figure 1).

4.6.2. Group Preparation of Content. Concerning group preparations, WhatsApp dominates the tools used, with 52 prospective teachers out of 56 (96.3\%) declaring the use of this application when preparing group content. (31.5\%) of prospective teachers said they use YouTube during group preparations, while just 14 prospective teachers use Facebook. As far as cloud-based tools are concerned, Google Drive is the most dominant, with $89.6 \%$ of prospective teachers using this tool during their group preparations. For other cloud-based computing tools, we find that $27.1 \%$ of prospective teachers use One Drive, and 16.7\% use Dropbox, while a minority ( 3 prospective teachers) use Cloud Drive. Microsoft's office tools also dominate the group preparations for prospective teachers. $98.1 \%$ of prospective teachers say they use these tools during their group preparations, while just two prospective teachers reported having used Open Office. E-mail exchanges are among the prominent tools used for pedagogical purposes by the majority of prospective teachers $(59.1 \%)$, while the training center platform and the e-portfolio are used equally (43.2\% for each) (see Figure 2).

4.7. What Motivates Prospective Teachers to Choose Specific Tools during Their Preparation? In the first part, we investigated the motivations that influence prospective teachers to 
TABLE 10: Motivations for choosing the tools during group preparation.

\begin{tabular}{lcc}
\hline Motivation when using tools for preparation & Number of prospective teachers & Percentage of observations \\
\hline Easy to handle & 45 & 81.8 \\
Online help services & 26 & 47.3 \\
Peer exchanges & 38 & 69.1 \\
Exchanges with trainers & 30 & 54.5 \\
Other motivations & 1 & 1.8 \\
\hline
\end{tabular}

TABLE 11: Essential services/resources for the tool used during content preparation.

\begin{tabular}{lcc}
\hline Essential services/resources on the tool used during content preparation & Number of prospective teachers & Percentage of observations \\
\hline Instant messaging, e-mail exchange & 43 & 79.6 \\
Access to the course & 26 & 48.1 \\
Online help & 16 & 29.6
\end{tabular}

choose between digital tools among all the digital arsenal at their disposal. These motivations concern the digital practices in general of prospective teachers, whereas, in this second part, the survey tackles the motivations of prospective teachers behind choosing digital tools during their preparation.

The responses of 45 prospective teachers (81.8\%) place the simplicity of the tool at the top of the list as a motivating factor for choosing a tool. Peer exchanges rank second (69.1\%) and those with trainers rank third (54.5\%). Online help services rank last among the suggested motivations $(47.3 \%)$. Table 10 summarizes the results obtained.

4.8. What Services/Resources Do You Consider Indispensable for the Digital Tool in Use? The digital tools used during preparation offer services and resources prospective teachers benefit from during their preparation of content. We questioned prospective teachers about the services and resources that they consider essential for the tools used.

$79.6 \%$ of prospective teachers affirmed that exchanges by instant messaging or by e-mail are the most indispensable dimension in the tools they often use. $48.1 \%$ of them consider access to content (courses, for example) to be the most important service offered by the tool used, while just $29.6 \%$ insist on online help services (see Table 11).

4.9. What Do Prospective Teachers and Trainers Produce during Training? Throughout the training, prospective teachers and their trainers create different types of documents. Trainers use their productions to train prospective teachers, whereas the latter produce content during individual or group preparations in order to pass the training modules and complete their internships.

The results show that $75 \%$ of prospective teachers produce digital content. Video-based content is significant (66.1\%), as well as images $(62.5 \%)$, while a minority of prospective teachers $(25 \%)$ claim to produce digital simulations. Paper-based materials are also an important part of the content produced by prospective teachers, with $71.4 \%$ of them stating that they produced paper-based content during the training. Concerning trainers, the results show that the

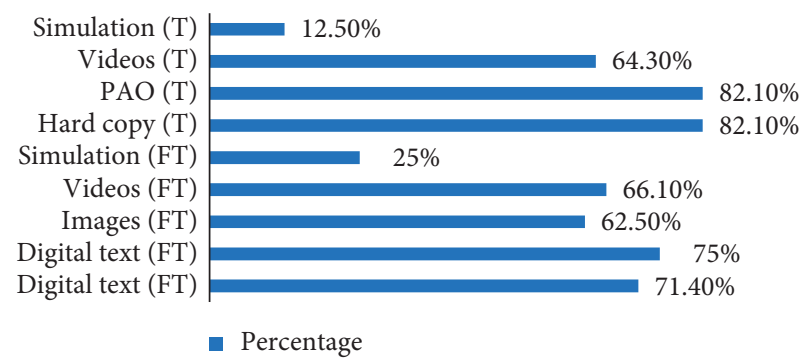

FIgURE 3: The types of trainer's outputs and prospective teachers during training. T: trainers, FT: prospective teachers.

content they produce is in the forms of print media and digital presentations. $82 \%$ of prospective teachers state that the majority of the trainers' content is paper-based and computer-assisted presentations (e.g., PowerPoint presentations). $64.3 \%$ say that video dominates their training content, while $12.5 \%$ indicate the integration of digital simulations by the trainers during training (see Figure 3 ).

4.10. Exchanges between Prospective Teachers and Their Trainers. We have classified exchanges with trainers under three categories: exchanges through social networks, exchanges through the digital tools of the cloud, and finally exchanges through digital pedagogical tools. Exchanges between prospective teachers and their trainers also cover written and voice modes of communication. As far as social networking tools are concerned, WhatsApp is the most dominant, as $97.6 \%$ claim to use WhatsApp when interacting with their trainers. $14.6 \%$ say they have used Facebook to interact with their trainers. A minority of $7.3 \%$ reported using YouTube for exchanges with trainers. Through the trainers' YouTube channels, students can leave comments to which trainers can respond. For cloud tools, exchanges through Google Drive are dominant, as $96.7 \%$ of prospective teachers confirm that they use Google Drive for exchanges with their trainers. Dropbox ranked second $(16.6 \%$ of prospective teachers), while Microsoft's One Drive is used by $13.3 \%$ of prospective teachers. 2 prospective teachers $(6.7 \%)$ stated that they use Apple's tool (Cloud Drive) when interacting with trainers. For pedagogical and professional 


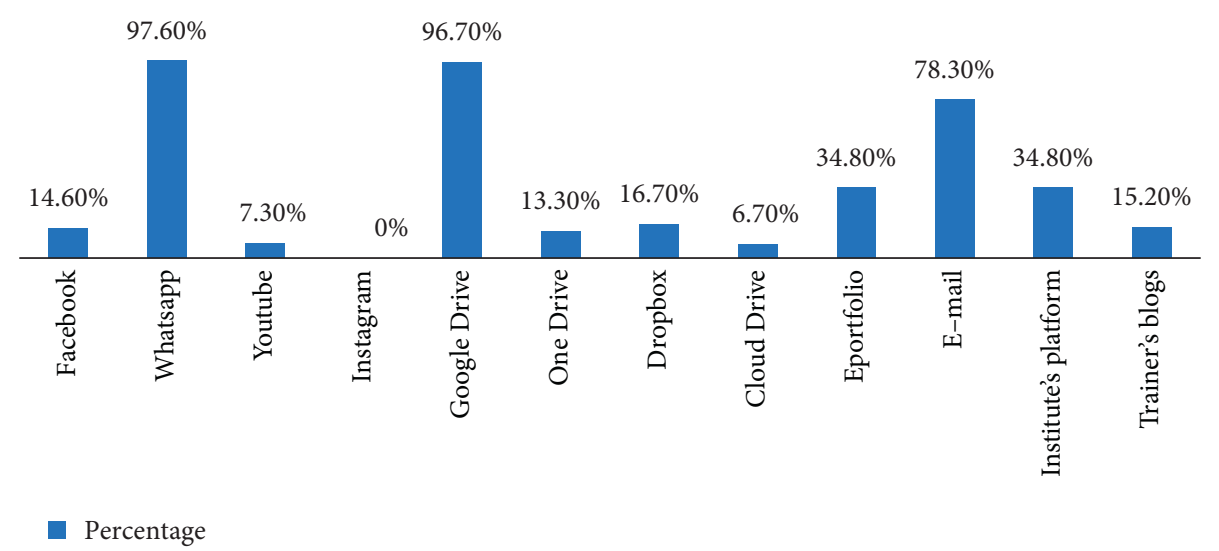

FIgURE 4: The digital tools used by prospective teachers during discussions with trainers.
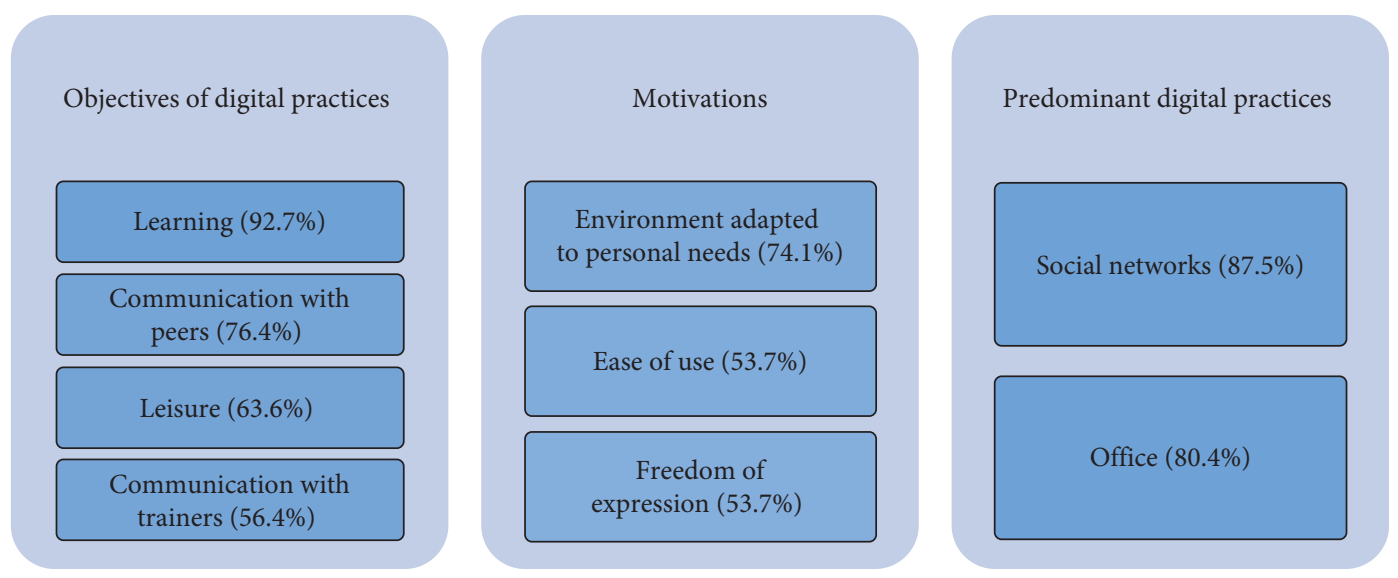

FIGURE 5: Predominant digital practices among prospective teachers, seen as a result of their goals and motivations.

tools, most exchanges are done through e-mail $(78.3 \%$ of prospective teachers say they use it for their exchanges with trainers). Exchanges through the institute's platform and the e-portfolio are affirmed by $34.8 \%$ of prospective teachers each. Finally, $15.2 \%$ of prospective teachers say they use their trainers' personal blogs as a tool for discussion (Figure 4). We also note that among the 56 prospective teachers, 8 prospective teachers stated that they had never received any feedback from their trainers and 6 declared that they had not had any type of exchange with the trainers.

\section{Discussion}

The objective of this article is to characterize the digital culture of prospective teachers, in terms of resources, digital tools used during content preparation, and also in terms of digital tools dominating their exchanges with trainers. The results obtained allow us to characterize the digital culture of prospective teachers and also understand the manifestations of this culture during training, content preparation, and also the exchanges with the trainers.

5.1. The Digital Culture of Prospective Teachers Tends toward Personalization. Personalization is understood in the sense of the use of tools or the harnessing of practices for personal/ recreational needs that are not among the pedagogical and professional expectations of the training. This aspect of personalization appears in the objectives revealed by prospective teachers, including leisure and communication with peers. Personalization also influences the motivations of prospective teachers to choose a specific digital practice. Prospective teachers are attracted to digital environments that meet their personal needs and also those that will allow them to express themselves freely. We accept that the dominant digital practices revealed are an immediate result of two factors: the teachers' objectives and motivations. The results of this study show the domination of social networks over the digital practices of prospective teachers, which confirms the personal nature of this digital culture (Figure 5).

Prospective teachers demonstrated frequent use of social networks in their digital practices; these social networks offer them opportunities, in terms of interactions with peers outside the walls of the school, shaping knowledge construction in unexpected or rather informal ways [14]. The findings of this study confirm the results noted in the studies [22-26], which emphasizes that prospective teachers use ICT on a personal level especially for communication, and also, they demonstrate a remarkable mastery of tools marking Web 2.0 (social networks, blogs, Google documents, etc.). 


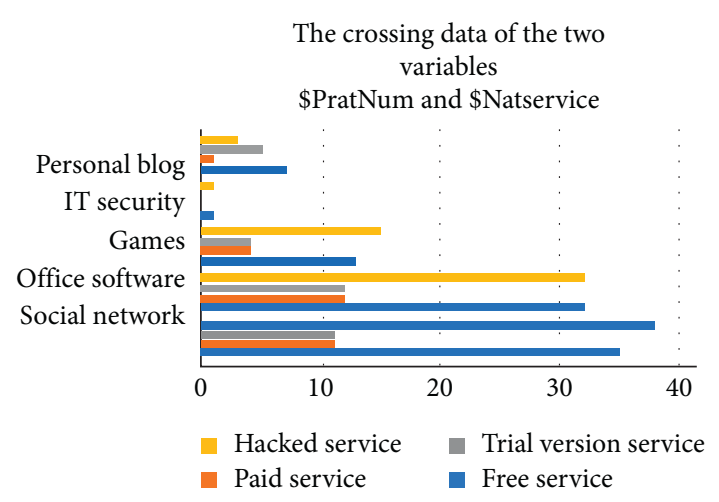

(a)

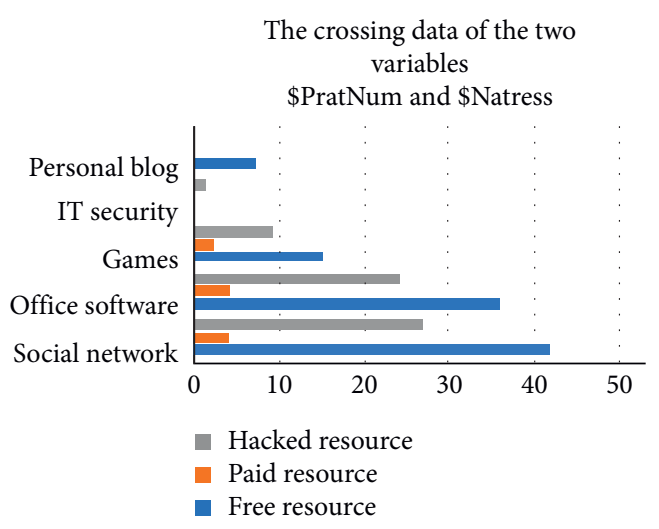

(b)

Figure 6: The crossing of the variable \$ PratNum with the two variables: (a) \$ Natservice and (b) \$ NatRess.

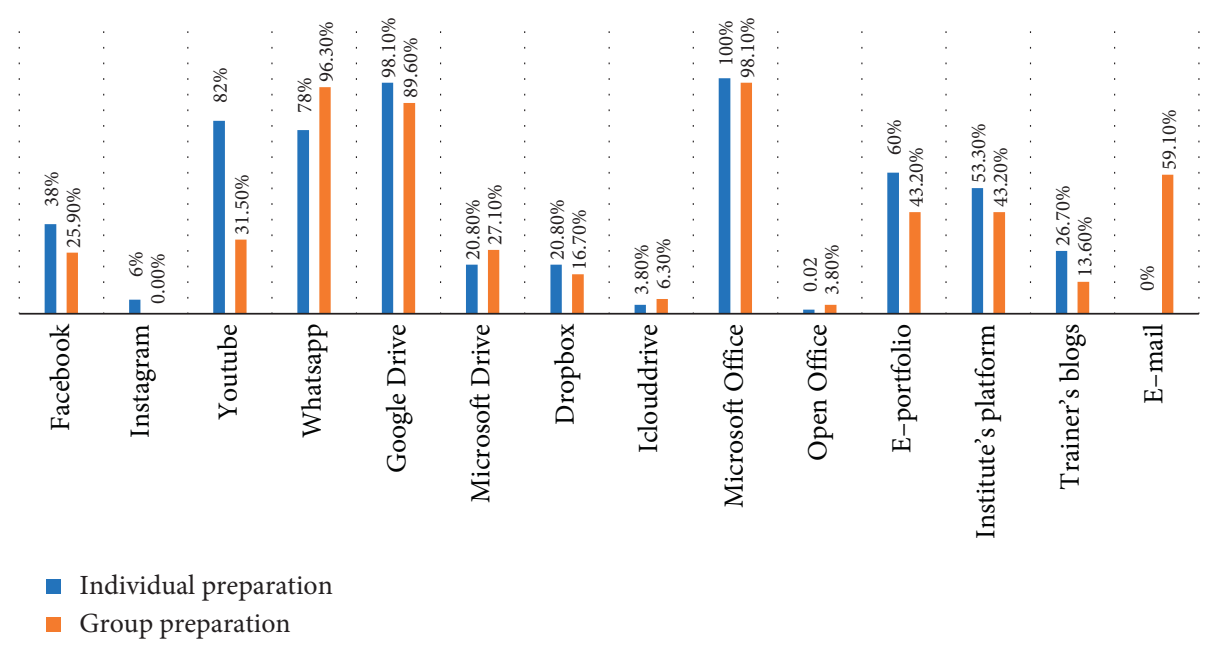

Figure 7: Comparison of the tools dominating the preparation of prospective teachers.

Despite the important role blogging plays as a digital space that allows prospective teachers to access an online tutor when needed [27-29], the results show a low tendency of prospective teachers to use personal blogs, with just $12.5 \%$ of them confirming the use of this tool. Several research studies have shown that the use of blogs has a positive impact and contributes to the professional development of prospective teachers $[30,31]$.

The results of this study highlight the nature of the services and resources manipulated by prospective teachers during their dominant digital practices. A cross-tabulation of the variable representing the digital practices \$ PratNum with each of the variables representing the nature of the \$ Natservice services and the nature of the \$NatRess resources allows us to characterize the nature of the services and resources for each category of practices. On social networks, we notice the domination of pirated and free services/resources, which indicates a trend among prospective teachers toward resources and services that meet their personal needs (such as sharing a paid book for free, sharing Netflix subscriptions, etc.). Free and pirated services/resources remain dominant over other categories of digital practices while paid services and resources remain in the minority (Figure 6).

5.2. The Importance of Digital Culture in the Preparation of Content throughout Training. The description of the digital tools that dominate content preparation activities by prospective teachers reveals the dominance of specific tools in each category (Figure 7).

5.2.1. The Use of Social Networks. The results reveal that WhatsApp dominates in prospective teachers' preparation activities (individual and in groups). These results are in line with the studies $[22-24,26]$ which confirmed that prospective teachers use ICT in their personal spheres to produce documents and also to communicate with their friends. They are also consistent with those of research on the analysis of professional competence in integrating ICT among prospective teachers in Quebec [32], where prospective teachers mark an effective use of digital technology 
for doing research, communicating information and problem-solving, building networks for exchanges, and continuing education in connection with their own teaching field. YouTube also marks the individual preparations of prospective teachers compared to those in groups; a difference is well noticed ( $82 \%$ declared that they use YouTube to prepare their content individually, while just $31 \%$ for group preparations). This significant use of YouTube highlights the importance of video as a resource and reference among prospective teachers. These results confirm the prominent position given to video in teacher training in the studies [33-36], where trainers used video to resolve misunderstandings and misinterpretations among novice teachers. With regard to WhatsApp and YouTube, we notice among prospective teachers a poor use of Facebook when preparing content. These results confirm Madge et al.'s [37] findings, who point out that students often use Facebook for social reasons and not necessarily for formal learning. The results of more recent studies [38-41] highlight that students value the use of Facebook as an educational artifact for acquiring new knowledge and also improving their skills.

5.2.2. The Use of Pedagogical Tools. We surveyed prospective teachers about the use of four digital educational tools (e-mail, e-portfolio, institutional platform, and trainers' blogs). The results reveal that the majority of prospective teachers $(60 \%)$ use digital e-portfolios during individual preparation of training content, compared to $43.2 \%$ during group preparations. The important role of the e-portfolio is confirmed by the results of the studies [42-45], highlighting that the use of the e-Portfolio reinforces the training experiences among prospective teachers, and allows trainers and trainees to identify professional skills they need to develop.

Regarding e-mail, $59.1 \%$ of prospective teachers declared using it during their group preparations. This result is in agreement with what studies $[32,46,47]$ pointed out, where prospective teachers prefer using electronic mail for any participation in exchange networks.

Prospective teachers show an important use of institutional platforms, which is confirmed by Villeneuve et al. [32] who reported that $45.2 \%$ of prospective teachers declared the use of educational and official websites to create networks for exchanges and lifelong training.

As for the personal blogs of trainers, they are hardly used during content preparation in the sense that $26.7 \%$ of prospective teachers stated that they use the trainers' blogs to prepare their individual content, while fewer of them (13.6\%) emphasized using these personal blogs for their group preparations. This underuse of the blog is also shown by Villeneuve et al. [32] who reported that only 3.3\% of the prospective teachers use forums and blogs to participate in exchange networks for self-development and personal growth.

With regard to office automation tools, Microsoft Office tools are very much used in the individual preparations of prospective teachers. These results confirm those of Lefebvre and Fournier [26] who emphasized that prospective teachers tend to use Microsoft office tools to produce documents related to their studies. They also confirm those highlighted by Poyet [6], by emphasizing that the majority of prospective teachers use a word processor, mainly Microsoft Word, to produce professional-looking writing and also personal correspondence.

\subsubsection{The Use of Cloud Storage Tools (Cloud Computing).} With the massification of digital tools offering cloud storage services, we asked prospective teachers about the use of the four best-known digital tools (Google Drive, Microsoft Drive, Dropbox, and iCloud Drive). The results show a major tendency of prospective teachers toward the Google Drive tool (98.1\% of prospective teachers declared using it during their individual preparations and $89.6 \%$ during group preparation). The use of Microsoft Drive and Dropbox is said to be identical for individual preparations, while a slight difference is noted for group preparations. Apple's iCloud Drive is reported as the least used tool by prospective teachers. These results abound on those revealed by $[32,48-50]$ noting that prospective teachers make use of Web 2.0 tools (Google tools, Dropbox, etc.) for various tasks during their preparations. The results obtained are in opposition to those of Wang et al. [51] describing the use of Web 2.0 tools and cloud computing tools by prospective teachers outside of school as poor.

The personal aspect of the digital culture of prospective teachers has given way to digital social media tools over other professional-looking tools, especially during individual preparations. We noticed strong domination of the two tools YouTube and WhatsApp on the individual preparations of prospective teachers compared to other tools such as e-portfolio, the digital platform of the training institute, and also e-mail. During group preparations, two tools show a considerable increase, WhatsApp for social networking tools and e-mail for professional tools. We also noted a significant difference in terms of usage between the two tools WhatsApp and e-mail (96.3\% of prospective teachers say they use WhatsApp during group preparations, while 59.1\% use e-mail).

5.3. The Nature of the Resources Produced. The results show that nondigitized content (paper-based) still retains an important place among the productions of prospective teachers and trainers. The use of video was equitable among prospective teachers and trainers. The digital textual productions and images among prospective teachers are important. These results are consistent with those of Poyet [6] which reveal that $90 \%$ of prospective teachers produce digital texts for their personal and professional work, while $83 \%$ of them produced images for personal use and $39 \%$ for professional objectives. Digital simulations are poorly used, with $25 \%$ of prospective teachers indicating that they produce digital simulations during preparations, and $12.5 \%$ of them indicated that their trainers use digital simulations as a pedagogical resource during training. 
5.4. Exchanges with Trainers. The issue of exchanges between prospective teachers and trainers is characterized by the diversity of the tools used. The results show that prospective teachers prefer a specific digital tool for each category of tools. The majority of social networking tools offer flexible communication services (instant messaging) and also exchange services. WhatsApp is reported by prospective teachers as the most used tool. This result is consistent with the results of [52-55]; the latter study states that the trainer/ prospective teacher relationship has changed due to the fact that trainers can still be reached by mobile phones at all times instead of waiting for a meeting at the office. Facebook is poorly used during exchanges, which does not concur with the results of [39], where the students state that using Facebook when carrying out their miniproject made it easier for them to communicate. For cloud tools, we notice a significant use of the Google Drive tool. This result does not agree with that of Wang et al. [51] who concluded that teachers do not use cloud-based tools much inside and outside of school. The use of other tools remains low compared to Google Drive. The digital tools that we have classified as pedagogical and professional are dominated by the use of emails when interacting with trainers. This result is confirmed by $[32,46]$; the researchers concluded that prospective teachers prefer e-mail during personal and professional exchanges. The use of e-portfolios and institutional platforms and blogs remains low when interacting with trainers.

Three tools dominate the exchanges of prospective teachers with their trainers. We note the significant place that WhatsApp occupies compared to the other two digital tools. This result reveals the importance of personal tools in discussions with trainers and thus reinforces the personal aspect of the digital culture of prospective teachers.

\section{Conclusion and Perspectives}

The results presented in this article show that the digital culture of prospective teachers is rooted in their personal use of various tools and resources. The digital practices of prospective teachers are characterized by frequent use of social networks and a low tendency to use institutional platforms and their trainers' blogs. The personal nature of this culture influences content preparation activities and exchanges with trainers. Content preparation (individually or in groups) often involves social networking tools (WhatsApp, YouTube). Pedagogical tools, such as the e-portfolio and institutional platforms, are of average use during preparations, while the use of electronic mail is important during group preparations. The use of "cloud" tools, such as Google Drive, is notable among these prospective teachers during their preparations. Interactions with trainers are dominated by WhatsApp, Google Drive, and e-mail; WhatsApp is more used when interacting with trainers.

The discussion highlights that these results are supported by those of several previous research studies and calls for further in-depth investigations on: (i) The self-coaching practices carried out by prospective teachers to make choices in the abundant supply of digital tools and resources available

(ii) The manifestations of the digital culture of trainers during their interactions with prospective teachers during their training course

(iii) The characteristics of the digital culture of prospective teachers in other educational cycles (the secondary cycle in the case of Morocco)

Regarding the possibilities of reinvesting our results in terms of intervention, it seems necessary to take into account the digital skills of prospective teachers developed outside the boundaries of school and the training institute. We adopt the point of view of Greenhow and Lewin [14], who suggested that education stakeholders need to rethink their judgment that labels young people's leisure time and digital practices on social networks as time-wasting or limiting to becoming educated and trained citizens. They invite all education stakeholders to understand the digital practices of young people on social networks in their professional and personal spheres. At the same time, taking into account that the digital culture of prospective teachers does not mean that they should think of it as an available resource that they can draw on for training purposes without guidance.

This study has limitations since it only targeted a random sample of prospective primary teachers, and therefore, the results cannot be generalized to all prospective teachers in Morocco. The future primary teachers come from different specialties, and the majority of them are not proficient in foreign languages, which made it necessary to conduct the survey in person and in their native language so as to avoid any linguistic ambiguities and break down communication barriers. This resulted in a loss of time and limited the possibility of expanding the sample size.

\section{Data Availability}

The data were collected by means of a paper questionnaire. A digital version is included in the article. The data were entered and analyzed using SPSS. These data are available upon request.

\section{Conflicts of Interest}

The authors declare no conflicts of interest.

\section{Authors' Contributions}

Conceptualization, formal analysis, and investigation were done by Y. O.; methodology was conducted by Y. O., F. K., and Z. A.; resources and software were provided by Y. O.; supervision and validation were performed by F. K. and Z. A.

\section{References}

[1] M. Prensky, "Digital natives," Digital Immigrants Part, vol. 1, p. 5, 2001.

[2] J. C. Duncheon and W. G. Tierney, "Changing conceptions of time: implications for educational research and practice," 
Review of Educational Research, vol. 39, Article ID $0034654313478492,2013$.

[3] E. G. Echenique, L. M. Molías, and M. Bullen, "Students in higher education: Social and academic uses of digital technology," vol. 12, no. 1, pp. 25-37, 2015.

[4] A. Fox and T. Bird, "The challenge to professionals of using social media: teachers in England negotiating personal-professional identities," Education and Information Technologies, vol. 22, pp. 647-675, 2017.

[5] A. D. Olofsson, G. Fransson, and J. O. Lindberg, "A study of the use of digital technology and its conditions with a view to understanding what "adequate digital competence" may mean in a national policy initiative," Educational Studies, vol. 46, no. 6, pp. 727-743, 2020.

[6] F. Poyet, "La culture numérique des jeunes professeurs des écoles peut-elle permettre de réduire l'écart entre natifs et immigrants du numérique?" Revue internationale des technologies en pédagogie universitaire, vol. 11, pp. 6-86, 2014.

[7] S. Bennett and K. Maton, "Beyond the "digital natives" debate: towards a more nuanced understanding of students' technology experiences," Journal of Computer Assisted Learning, vol. 26, no. 5, pp. 321-331, 2010.

[8] B. Barron, S. E. Walter, C. K. Martin, and C. Schatz, "Predictors of creative computing participation and profiles of experience in two Silicon Valley middle schools," Computers and Education, vol. 54, no. 1, pp. 178-189, 2010.

[9] S. Balbay, I. Pamuk, T. Demir, and C. Dogan, "Issues in prospective and in-service teacher-training programs for university English instructors in Turkey," Journal of Language and Linguistics Studies, vol. 14, no. 3, pp. 42-80, 2018.

[10] M. Lahchimi, "La réforme de la formation des enseignants au Maroc," Revue internationale d'éducation de Sèvres, vol. 69, pp. 21-26, 2015.

[11] J. Greene, "Ethnography, step by step (2nd edition), by david M. Fetterman, thousand oaks, CA: sage, 1998," The American Journal of Evaluation, vol. 21, no. 3, pp. 389-390, 2000.

[12] L. B. Bayeva, "Electronic culture: the experience of philosophical analysis," Questions of Philosophy, vol. 5, pp. 75-83, 2013.

[13] C. Fluckiger, "L'école à l'épreuve de la culture numérique des élèves," Revue française de pédagogie, vol. 163, pp. 51-61, 2008.

[14] C. Greenhow and C. Lewin, "Social media and education: reconceptualizing the boundaries of formal and informal learning," Learning Media and Technology, vol. 41, no. 1, pp. 1-25, 2016.

[15] S. I. Chernykh and V. I. Parshikov, "Digital culture as a human phenomenon," Professional Education in the Modern World, vol. 6, no. 4, 2016.

[16] B. B. Krivosheev, "Electronic culture: the necessity of interdisciplinary study approach," Humanities and Social Sciences, vol. 6, 2013 Vestnik of Baltik Federal University named after I. Kant. Series.

[17] A. Babori, A. Zaid, and H. F. Fassi, "Research on MOOCs in major referred journals: the role and place of content," The International Review of Research in Open and Distributed Learning, vol. 20, no. 3, 2019.

[18] J. H. Petersen, P. M. Fayers and D. Machin, Quality of Life. Assessment, Analysis and Interpretation, Wiley, Chichester, UK, No. of pages: Xii +404. Price: $£ 60.00$. ISBN 0-471-968617, 2001.

[19] T. Karsenti, "Comment le recours aux TIC en pédagogie universitaire peut favoriser la motivation des étudiants: Le cas d'un cours médiatisé sur le Web," L'intégration des TIC en éducation: enjeux, défis et perspectives, vol. 4, no. 3, 1997.
[20] I. O. Panisoara, I. Lazar, G. Panisoara, R. Chirca, and A. S. Ursu, "Motivation and continuance intention towards online instruction among teachers during the COVID-19 pandemic: the mediating effect of burnout and technostress," International Journal of Environmental Research and Public Health, vol. 17, Article ID 8002, 2020.

[21] A. Valentín, "Motivation and learning strategies in the use of ICTs among university students," Computers and Education, vol. 61, pp. 52-58, 2013.

[22] G. Bjo, J. C. C. Rubio, and O. E. Hatlevik, "Student teachers' responsible use of ICT: examining two samples in Spain and Norway," Computers and Education, vol. 152, Article ID 103877, 2020.

[23] C. S. Chai, "The Internet and Teacher education: traversing between the digitized world and schools," Internet and Higher Education, vol. 14, pp. 3-9, 2011.

[24] A. Guzman and M. Nussbaum, "Teaching competencies for technology integration in the classroom," Journal of Computer Assisted Learning, vol. 25, no. 5, pp. 453-469, 2009.

[25] E. Ifinedo, J. Rikala, and T. Hämäläinen, "Factors affecting Nigerian teacher educators' technology integration: considering characteristics, knowledge constructs, ICT practices and beliefs," Computers and Education, vol. 146, Article ID 103760, 2020.

[26] S. Lefebvre and H. Fournier, "Utilisations personnelles, professionnelles et pédagogiques des TIC par de futurs enseignants et des enseignants," Revue internationale des technologies en pédagogie universitaire, vol. 11, no. 2, pp. 6-82, 2014.

[27] Y. Arouri, "How Jordanian university students perceive the opportunities and challenges of using Facebook as a supplementary learning resource?" International Journal of Emerging Technologies in Learning (iJET), vol. 10, no. 1, p. 46, 2015.

[28] L. Biberman-Shalev, "Personal blogs or communal blogs? Prospective teachers' perceptions regarding the contribution of these two platforms to their professional development," Teaching and Teacher Education, vol. 69, pp. 253-262, 2018.

[29] A. M. Lazar, "Preservice teachers' varied experiences in urban literacy practica: a challenge for teacher educators," Teaching and Teacher Education, vol. 9, 2018.

[30] A. Hramiak, H. Boulton, and B. Irwin, "Trainee teachers' use of blogs as private reflections for professional development," Learning, Media and Technology, vol. 34, no. 3, pp. 259-269, 2009.

[31] E. Tang and C. Lam, "Building an effective online learning community (OLC) in blog-based teaching portfolios," The Internet and Higher Education, vol. 20, pp. 79-85, 2014.

[32] S. Villeneuve, T. Karsenti, C. Raby, and H. Meunier, "Les futurs enseignants du Québec sont-ils technocompétents?: une analyse de la compétence professionnelle à intégrer les TIC," Revue internationale des technologies en pédagogie universitaire, vol. 9, no. 1-2, p. 78, 2012.

[33] V. L. Barth, V. Piwowar, I. R. Kumschick, D. Ophardt, and F. Thiel, "The impact of direct instruction in a problem-based learning setting. effects of a video-based training program to foster preservice teachers' professional vision of critical incidents in the classroom," International Journal of Educational Research, vol. 95, pp. 1-12, 2019.

[34] S. Chaliès, C. Gaudin, and H. Tribet, "Exploiter la vidéo dans les dispositifs de formation des enseignants novices: conceptualisation et discussion théoriques à partir d'une étude de cas en EPS," Revue française de pédagogie, vol. 21, pp. 5-24, 2015. 
[35] F. Ulusoy, "Prospective teachers' skills of attending, interpreting and responding to content-specific characteristics of mathematics instruction in classroom videos," Teaching and Teacher Education, vol. 94, Article ID 103103, 2020.

[36] K. E. Weber, B. Gold, C. N. Prilop, and M. Kleinknecht, "Promoting pre-service teachers' professional vision of classroom management during practical school training: effects of a structured online- and video-based self-reflection and feedback intervention," Teaching and Teacher Education, vol. 76, pp. 39-49, 2018.

[37] C. Madge, J. Meek, J. Wellens, and T. Hooley, "Facebook, social integration and informal learning at university: "It is more for socialising and talking to friends about work than for actually doing work"," Learning, Media and Technology, vol. 34, pp. 141-155, 2009.

[38] H. B. Rebah and G. M. Dabove, Distances et médiations des savoirs, 2017.

[39] C. Saini and J. Abraham, "Implementing Facebook-based instructional approach in pre-service teacher education: an empirical investigation," Computers and Education, vol. 128, pp. 243-255, 2019.

[40] P. Sendurur, "Examination of the social network sites usage patterns of prospective teachers," Computers in Human Behavior, vol. 7, 2015.

[41] A. Unal, "Social networking purposes of prospective teachers," Procedia - Social and Behavioral Sciences, vol. 186, pp. 825-828, 2015.

[42] F. Baier and M. Kunter, "Construction and validation of a test to assess (pre-service) teachers' technological pedagogical knowledge (TPK)," Studies in Educational Evaluation, vol. 67, Article ID 100936, 2020.

[43] P. Colás-Bravo, P. Magnoler, and J. Conde-Jiménez, "Identification of levels of sustainable consciousness of Teachers in training through an e-portfolio," Sustainability, vol. 10, no. 10, Article ID 3700, 2018.

[44] S. Kearney and J. Maakrun, "Let's get engaged: the nexus between digital technologies, engagement and learning," Education Sciences, vol. 13, Article ID 10120357, 2020.

[45] J. Rodríguez, "El e-portfolio de competencias en los procesos de acompañamiento de enseñanza y aprendizaje escolar," Revista Iberoamericana de Evaluación Educativa, vol. 5, 2012.

[46] M. Alzubi and M. Sabha, "Using mobile-based email for English foreign language learners," Turkish Online Journal of Educational Technology, vol. 12, pp. 178-186, 2013.

[47] J. Bloch, "Student/teacher interaction via email: the social context of Internet discourse," Journal of Second Language Writing, vol. 11, no. 2, pp. 117-134, 2002.

[48] S. Baltaci-Goktalay and Z. Ozdilek, "Prospective teachers' perceptions about web 2.0 technologies," Procedia Social and Behavioral Sciences, vol. 2, no. 2, pp. 4737-4741, 2010.

[49] S. Kavanoz, "Prospective teachers' self-efficacy perceptions on web pedagogical content knowledge," Computers \& Education, vol. 85, 2015.

[50] A. Sadaf, "Exploring prospective teachers' beliefs about using Web 2.0 technologies in K-12 classroom," Computers and Education, vol. 59, no. 3, pp. 937-945, 2012.

[51] S.-K. Wang, H.-Y. Hsu, T. Campbell, D. C. Coster, and M. Longhurst, "An investigation of middle school science teachers and students use of technology inside and outside of classrooms: Considering whether digital natives are more technology savvy than their teachers," Educational Technology Rsearch and Development, vol. 62, pp. 637-662, 2014.
[52] R. Alshammari, M. Parkes, and R. Adlington, "Using WhatsApp in EFL instruction with Saudi Arabian university students," Arab World English Journal, vol. 8, no. 4, 2017.

[53] F. Deschenaux, C. Roussel, and M. Alexandre, "Se former a l'enseignement en alternance educative virtuelle : la situation des enseignants de la formation professionnelle a l'uqar," Transformation, vol. 14, 2011.

[54] J. Jain, J. Eddy Luaran, and N. B. A. Rahman, "Learning beyond the walls: the role of WhatsApp groups," Envisioning the Future of Online Learning, pp. 447-457, 2016.

[55] J. Lam, "Collaborative learning using social media tools in a blended learning course," in Hybrid Learning: Innovation in Educational Practices (Lecture Notes in Computer Science), S. K. S. Cheung, L. Kwok, and H. Yang, Eds., , pp. 187-198, Springer International Publishing, 2015. 